University of Nebraska - Lincoln

DigitalCommons@University of Nebraska - Lincoln

Faculty Publications in the Biological Sciences

Papers in the Biological Sciences

2007

\title{
Electrochemical Stimulation of Microbial Perchlorate Reduction
}

J. Cameron Thrash

University of California, Berkeley, joz.ennn@gmail.com

J. Ian Van Trump

University of California, Berkeley

Karrie A. Weber

University of Nebraska-Lincoln, kweber@unl.edu

Elisabeth Miller

Southern Illinois University Carbondale

Laurie A. Achenbach

Southern Illinois University Carbondale, laurie@micro.siu.edu

See next page for additional authors

Follow this and additional works at: https://digitalcommons.unl.edu/bioscifacpub

Part of the Life Sciences Commons

Thrash, J. Cameron; Van Trump, J. Ian; Weber, Karrie A.; Miller, Elisabeth; Achenbach, Laurie A.; and Coates, John D., "Electrochemical Stimulation of Microbial Perchlorate Reduction" (2007). Faculty Publications in the Biological Sciences. 203.

https://digitalcommons.unl.edu/bioscifacpub/203

This Article is brought to you for free and open access by the Papers in the Biological Sciences at DigitalCommons@University of Nebraska - Lincoln. It has been accepted for inclusion in Faculty Publications in the Biological Sciences by an authorized administrator of DigitalCommons@University of Nebraska - Lincoln. 


\section{Authors}

J. Cameron Thrash, J. Ian Van Trump, Karrie A. Weber, Elisabeth Miller, Laurie A. Achenbach, and John D. Coates 


\section{Electrochemical Stimulation of Microbial Perchlorate Reduction}

J. CAMERON THRASH, ${ }^{\dagger}$

J. IAN VAN TRUMP, ${ }^{\dagger}$ KARRIE A. WEBER, ${ }^{\dagger}$

ELISABETH MILLER,

LAURIE A. ACHENBACH, * AND

J O H N D. COATE S $*, \uparrow, \S$

Department of Plant and Microbial Biology,

University of California, Berkeley, California 94720,

Department of Microbiology, Southern Illinois University,

Carbondale, Illinois 62901, and Earth Sciences Division,

Ernest Orlando Lawrence Berkeley National Laboratory,

Berkeley, California 94720

As part of our studies into the diversity of dissimilatory perchlorate reducing bacteria (DPRB) we investigated the reduction of perchlorate in the cathodic chamber of a bioelectrical reactor (BER). Our results demonstrated that washed cells of Dechloromonas and Azospira species readily reduced $90 \mathrm{mg} \mathrm{L}^{-1}$ perchlorate in the BER with 2,6anthraquinone disulfonate (AODS) as a mediator. No perchlorate was reduced in the absence of cells or AODS, or in an open-circuit control. Similar results were observed when a natural microbial community was inoculated into a fed-batch BER. After 70 days of operation, a novel DPRB, strain VDY, was isolated which readily reduced perchlorate in a mediatorless BER. Continuous up-flow BERs (UFBERs) were seeded with active cultures of strain VDY, and perchlorate at a volumetric loading of $60 \mathrm{mg} \mathrm{L}^{-1}$ day $^{-1}$ was successfully removed. Gas phase analysis indicated that low levels of $\mathrm{H}_{2}$ produced at the cathode surface through electrolysis may mediate this metabolism. The results of these studies demonstrate that biological perchlorate remediation can be facilitated through the use of a cathode as the primary electron donor, and that continuous treatment in such a system approaches current industry standards. This has important implications for the continuous treatment of this critical contaminant in industrial waste streams and drinking water.

\section{Introduction}

Perchlorate $\left(\mathrm{ClO}_{4}^{-}\right)$, a soluble anion, is known to affect mammalian thyroid hormone production potentially leading to neonatal neuropsychological development deficiencies $(1-3)$. It is predominantly a synthetic compound with a broad assortment of industrial applications ranging from pyrotechnics to lubricating oils (4). Ammonium perchlorate represents $90 \%$ of all perchlorate salts manufactured and is used as an energetics booster or oxidant in solid rocket fuels and munitions (4). Its presence in the environment primarily results from legal historical discharge of unregulated manufacturing waste streams, disposal pond leachate, and the

\footnotetext{
* Corresponding author: phone: (510)643-8455; fax: (510)6424995; e-mail: jcoates@nature.berkeley.edu.

${ }^{\dagger}$ University of California.

${ }^{\ddagger}$ Southern Illinois University.

${ }^{\S}$ Ernest Orlando Lawrence Berkeley National Laboratory.
}

periodic servicing of military inventories (5-7). Although a powerful oxidant, under most environmental conditions perchlorate is quite stable owing to the high energy of activation associated with its reduction $(5,6)$. Perchlorate salts readily dissociate in aqueous phases because of the large molecular volume and single anionic charge (5). Furthermore, perchlorate does not significantly sorb to soils or sediments, and in the absence of any biological interactions, its mobility and fate are largely influenced by the hydrology of the environment (8).

Remediation efforts for perchlorate contamination have focused primarily on microbial reduction $(5,9)$. Many recent studies have demonstrated that specialized microorganisms have evolved that can grow by the anaerobic reductive dissimilation of perchlorate into innocuous chloride $(9,10)$. More than 40 dissimilatory perchlorate-reducing bacteria (DPRB) are now in pure culture (9), and organisms capable of this metabolism are known to be ubiquitous in soil and sedimentary environments (11) making in-situ treatments relatively straightforward. Furthermore, several bioreactor designs are available for the ex-situ biological attenuation of perchlorate-contaminated waters. Recently, some of these reactor designs were conditionally approved by the California Department of Health Services for application in the treatment of perchlorate contaminated drinking water (URL http: / / www.safedrinkingwater.com / archive / sdwn051502.htm). However, these systems are still dependent on the continual addition of a chemical electron donor to sustain microbial activity and are always subject to biofouling issues $(12,13)$. In addition, a residual labile electron donor in the reactor effluent can stimulate microbial growth in water distribution systems and contribute to the formation of potentially toxic trihalomethanes during disinfection by chlorination $(14,15)$. To overcome these problems, chemolithotrophic perchlorate-reducing bioreactors utilizing $\mathrm{H}_{2}$ as an electron donor have been proposed $(16,17)$. However, $\mathrm{H}_{2}$ in bulk quantities is difficult to handle and is publicly perceived as representing a significant disaster threat due to its inherent explosive nature. Alternative inorganic electron donors including $\mathrm{Fe}(\mathrm{II}), \mathrm{S}^{0}$, or $\mathrm{H}_{2} \mathrm{~S}$ may offer a more practical approach; however, regular additions of these compounds to bioreactors are still required. Furthermore, $\mathrm{H}_{2} \mathrm{~S}$ is a malodorous toxic compound which can cause corrosion issues while the particulate ferric (hydr) oxides resulting from $\mathrm{Fe}(\mathrm{II})$ oxidation result in unpleasant taste and odor, clogged pump and treatment systems, and anodic corrosion of steel pipes and distribution lines $(18-20)$.

Here we investigated the use of a negatively charged electrode (cathode) in the working chamber of a bioelectrical reactor (BER) as an electron donor for microbial perchlorate reduction. In this instance, the DPRB use the electrons on the electrode surface either directly or indirectly through an electron shuttle as a source of reducing equivalents for perchlorate reduction, while assimilating carbon from $\mathrm{CO}_{2}$ or alternative available carbon sources. Such a process has the advantage of long-term, low-maintenance operation with ease of online monitoring and control while limiting the injection of additional chemicals into the water treatment process. This would negate downstream issues associated with corrosion and biofouling of distribution systems and the production of toxic disinfection byproducts.

\section{Materials and Methods}

BER Construction. The BER was constructed with two 50 $\mathrm{mm}$ diameter glass chambers with three sample ports, connected with a $30 \mathrm{~mm}$ pinch clamp assembly (Laboratory 
Glass Apparatus, Berkeley, CA). Chambers were separated with a cation exchange membrane (Nafion 117). Sample ports were sealed with thick butyl rubber stoppers and aluminum crimp seals. The electrodes were $2.5 \times 1.25 \times 7.5 \mathrm{~cm}^{3}$ unpolished graphite (G-10 Graphite Engineering and Sales, Greenville, MI) connected with watertight threaded fittings (Impulse, San Diego, CA) to wires and sealed with conductive silver epoxy (Epoxy Technology, Billerica, MA). Wires were fed through stoppers in the top of each chamber. Prior to initial use and before each use thereafter, the electrodes were washed repeatedly in $1 \mathrm{~N} \mathrm{HCl}$ to remove residual minerals and any biomass buildup and rinsed in sterile deionized water. The silver $(\mathrm{Ag} / \mathrm{AgCl})$ reference electrode (Warner Instruments, Hamden, CT) was threaded through a butyl stopper after sterilization with ethanol. Prior to inoculation, the chambers and all stoppers were autoclaved to ensure sterility and subsequently flushed with filter sterilized $(0.22$ $\mu$ m pore size) $\mathrm{N}_{2}-\mathrm{CO}_{2}(80: 20 ; \mathrm{v} / \mathrm{v})$ gas. Throughout the study, the anodic chamber was filled with presterilized, anaerobic $30 \mathrm{mM}\left(1.83 \mathrm{~g} \mathrm{~L}^{-1}\right)$ bicarbonate buffer $(\mathrm{pH}$ 6.8) while the cathodic chamber was filled with either bicarbonate buffer (cell suspensions) or basal growth medium (enrichment/ growth studies) outlined below and amended with perchlorate as the sole electron acceptor. Unless otherwise noted, $500 \mu \mathrm{M}$ AQDS (183 $\mathrm{mg} \mathrm{L}^{-1}$ ) was added as an appropriate electron shuttle. The growth medium was further amended with acetate $\left(5.9 \mathrm{mg} \mathrm{L}^{-1}\right)$ as a suitable carbon source. Both chambers were bubbled continuously with filtered $(0.22 \mu \mathrm{m}$ pore size) $\mathrm{N}_{2}-\mathrm{CO}_{2}(80: 20 ; \mathrm{v} / \mathrm{v})$ gas to ensure anaerobic operation and maintenance of $\mathrm{pH}$ throughout operation. A custom-built potentiostat (Berkeley BioScientific; Dublin, Ireland) was connected to a digital multimeter (Thurlby Thandar Instruments, Cambridgeshire, U.K.) for control of the electrochemical potential.

When run in continuous-flow experiments, $1 / 16$ in. i.d. Norprene tubing (Saint Gobain Performance Plastics, Paris, France) was threaded through $1 \mathrm{~mL}$ syringe housings embedded in butyl stoppers in the ports of the cathodic chamber. Flow was established using a peristaltic pump (Rainin, Oakland, CA). The cathodic chamber was filled with powdered graphite that was held in place by a thin $(0.5 \mathrm{~cm})$ layer of acid washed sand. A single unpolished graphite (G10 Graphite Engineering and Sales, Greenville, MI) electrode connected with watertight threaded fittings (Impulse, San Diego, CA) to wires and sealed with conductive silver epoxy (Epoxy Technology, Billerica, MA) was plunged into the powdered graphite bed to ensure electrical conductivity. The influent was pumped in an up-flow mode through the graphite bed, which was maintained at a potential difference of $500 \mathrm{mV}$ relative to the reference electrode. The reactor was inoculated ( $10 \%$ by volume) with an active perchloratereducing culture of strain VDY which was spun down and resuspended in an equal volume of anoxic sterile growth media prior to injection into the graphite bed through the influent port.

Medium and Culturing Conditions. All pure cultures were obtained from lab stocks except strain VDY which was isolated in this study. Standard anaerobic culturing techniques were used throughout (21-23). The medium was boiled and cooled under $\mathrm{N}_{2}-\mathrm{CO}_{2}$ (80:20) to remove dissolved $\mathrm{O}_{2}$ and then dispensed into anaerobic pressure tubes or serum bottles under $\mathrm{N}_{2}-\mathrm{CO}_{2}$, capped with thick butyl rubber stoppers, and sterilized by autoclaving. The basal medium was the bicarbonate-buffered freshwater medium that had previously been used for culturing perchlorate-reducing bacteria (24). Unless otherwise noted, sodium salts of acetate and perchlorate at $10 \mathrm{mM}$ each (590 and $990 \mathrm{mg} \mathrm{L}^{-1}$, respectively) were added from sterile anoxic aqueous stocks as the electron donor and acceptor, respectively.
Alternative electron donors and acceptors were added from sterile anoxic aqueous stocks prepared from the sodium salts to give final concentrations of $10 \mathrm{mM}$ in the culture medium. All culture incubations were performed at room temperature without agitation in the dark.

Washed Cell Suspensions. Cells were pregrown anaerobically in $1 \mathrm{~L}$ volumes with acetate $\left(590 \mathrm{mg} \mathrm{L}^{-1}\right)$ as the electron donor and perchlorate $\left(990 \mathrm{mg} \mathrm{L}^{-1}\right)$ as the sole electron acceptor. After $18 \mathrm{~h}$ incubation, the cells were harvested by centrifugation $(3000 \times g)$ and washed with anoxic bicarbonate buffer $\left(2.5 \mathrm{~g} \mathrm{~L}^{-1}\right)$ under a $\mathrm{N}_{2}-\mathrm{CO}_{2}(80: 20 ; \mathrm{v} / \mathrm{v})$ headspace. Washed cells were resuspended in anoxic bicarbonate buffer $(1 \mathrm{~mL})$ and sealed in a $10 \mathrm{~mL}$ serum vial with a butyl stopper under the same headspace.

DPRB Isolation. Perchlorate-reducing enrichments were established by transferring 1 g of electrode surface scrapings into $9 \mathrm{~mL}$ of prepared anoxic medium under a gas stream of $\mathrm{N}_{2}-\mathrm{CO}_{2}(80: 20 ; \mathrm{v} / \mathrm{v})$. Acetate $\left(590 \mathrm{mg} \mathrm{L}^{-1}\right)$ was the electron donor, and perchlorate $\left(990 \mathrm{mg} \mathrm{L}^{-1}\right)$ was the electron acceptor. Incubations were done at $30^{\circ} \mathrm{C}$ in the dark. Positive enrichments were identified by visual increase in optical density and by microscopic examination. Once a positive enrichment was established, the perchlorate-reducing culture was transferred (10\% inoculum) into $9 \mathrm{~mL}$ of fresh anoxic medium. Isolated colonies were obtained from transfers of positive enrichments by the standard agar shake-tube technique outlined previously (24) with acetate as the sole electron donor and perchlorate (590 and $990 \mathrm{mg} \mathrm{L}^{-1}$, respectively) as the sole electron acceptor.

16s rRNA Gene Sequencing and Analysis. Cells from 10 - $\mathrm{mL}$ cultures of the isolated perchlorate reducing bacteria were harvested by centrifugation, resuspended in $40 \mu \mathrm{L}$ sterile water, and lysed by the addition of $5 \mu \mathrm{L}$ chloroform with a 10 min incubation at $95{ }^{\circ} \mathrm{C}$. Primers specific to bacterial 16S rDNA (8F: 5'-AGAGTTTGATCCTGGCTCAG-3'; 1525R: 5'-AAGGAGGTGATCCAGCC-3') were used in a polymerase chain reaction (PCR) that consisted of $10 \mathrm{mM}$ Tris- $\mathrm{HCl}(\mathrm{pH}$ 9.0), $50 \mathrm{mM} \mathrm{KCl}, 0.1 \%$ Triton $\mathrm{X}-100,1.2 \mathrm{mM} \mathrm{MgCl}, 0.2 \mathrm{mM}$ each dNTP, $75 \mathrm{ng}$ of each primer, $0.5 \mu \mathrm{L}$ Taq polymerase (Gibco/BRL), and $1 \mu \mathrm{L}$ of lysed cells in a $50 \mu \mathrm{L}$ reaction. Amplifications were performed at these parameters: $94^{\circ} \mathrm{C}$ for $3 \mathrm{~min}$, followed by 30 cycles of $94^{\circ} \mathrm{C}$ for $1 \mathrm{~min}, 55^{\circ} \mathrm{C}$ for $1 \mathrm{~min}$, and $72^{\circ} \mathrm{C}$ for $2 \mathrm{~min}$ with a final incubation of $10 \mathrm{~min}$ at $72{ }^{\circ} \mathrm{C}$. The amplification products were gel-purified (GeneClean II, BIO101) and cycle sequenced (ThermoSequenase, Amersham) using internal primers. Sequence entry and manipulation was performed with the MacVector 8.1 sequence analysis software program for the Macintosh (Oxford Molecular). Sequences of select 16S rRNAs were downloaded from the Ribosomal Database Project (25) and Genbank (26) into the computer program SeqApp (27). The partial 16S rDNA sequence (636 bp) from strain VDY was manually added to the alignment using secondary structure information for proper alignment. Distance analysis of the aligned sequences was performed using PAUP* 4.0d65 (28).

Analytical Methods. All experimental analyses were performed in triplicate to ensure reproducibility, and the results are expressed as the mean of these determinations. The concentration of perchlorate in cultures was determined using ion chromatography as previously described (29). Cell growth in active cultures was monitored by optical density at $600 \mathrm{~nm}(\mathrm{OD} 600)$, and by total direct cell count using phasecontrast microscopy as previously described (11).

\section{Results}

Bioelectrical Reduction of Perchlorate by Pure Cultures of DPRB. Active washed cell suspensions of Dechloromonas agitata, D. aromatica, and Azospira suillum, three representatives of the environmentally dominant perchlorate reducing bacterial genera, readily reduced $99 \mathrm{mg} \mathrm{L}^{-1}$ per- 


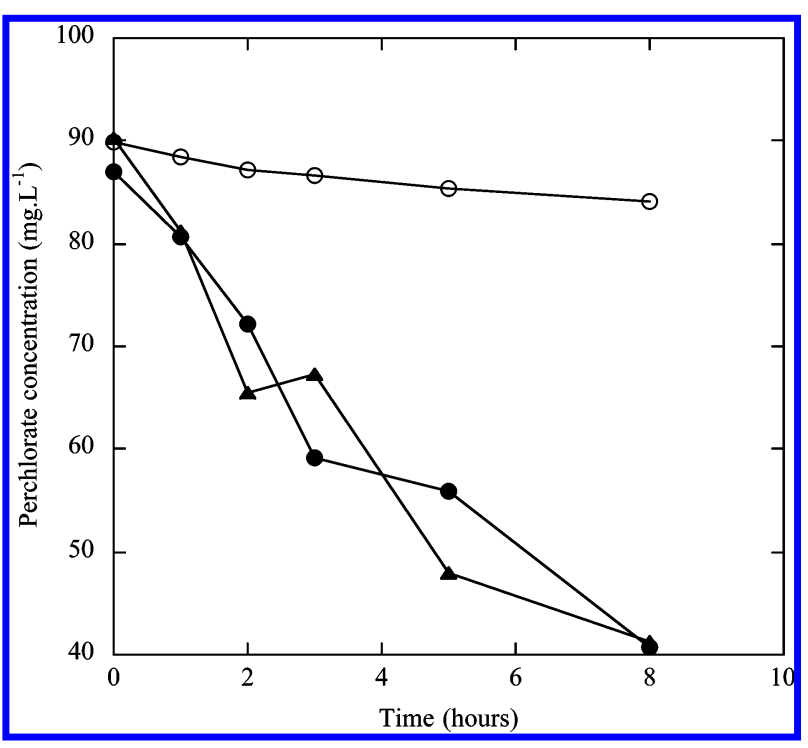

FIGURE 1. Perchlorate reduction by washed whole cell suspensions of Azospira suillum strain PS using acetate or the BER cathode as the primary electron donor. Closed circles depict perchlorate reduction in the $B E R$, closed triangles depict perchlorate reduction with acetate $\left(50 \mathrm{mg} \mathrm{L}^{-1}\right)$, and open circles depict perchlorate reduction in the open-circuit control.

chlorate over a $24 \mathrm{~h}$ trial when incubated in the cathodic chamber of the electrochemical cell at a poised potential of $-450 \mathrm{mV}$ (relative to the Ag reference electrode) containing $183 \mathrm{mg} \mathrm{L}^{-1}(500 \mu \mathrm{M})$ 2,6-anthraquinone disulfonate (AQDS) (Figure 1). In all cases, the rate and extent of perchlorate reduction were almost identical to those observed in the positive control to which acetate $\left(59 \mathrm{mg} \mathrm{L}^{-1}\right)$ was added as the sole electron donor (Figure 1). In contrast, no significant perchlorate reduction was observed in identical incubations in which the electrical circuit was incomplete (open-circuit control) (Figure 1), suggesting that perchlorate reduction was an enzymatically mediated reaction using electrons derived from the surface of the cathode. Although perchlorate was continuously removed, none of the tested DPRB (D. agitata, D. aromatica, or A. suillum) grew in the BER (as determined by microscopic observation and change in optical density at $600 \mathrm{~nm}$ ), when similar experiments were performed in the BER using basal growth medium amended with $5.9 \mathrm{mg} \mathrm{L}^{-1}$ acetate as a suitable carbon source (data not shown).

In all incubations, no significant perchlorate reduction occurred relative to the open-circuit control if the AQDS was omitted from the medium even after an extended incubation period of $72 \mathrm{~h}$ (data not shown). In order to ensure that the observed perchlorate reduction was not due to the biological catabolism of the added AQDS, perchlorate concentrations were monitored in active anaerobic cultures of D. agitata incubated with AQDS as the sole electron donor in sealed serum vials. Again, no perchlorate reduction was observed unless acetate was added as an additional electron donor (data not shown). In contrast, if $\mathrm{AH}_{2} \mathrm{DS}$ (the reduced hydroquinone form of AQDS) was provided, $D$. agitata readily reduced the perchlorate with the concomitant oxidation of the $\mathrm{AH}_{2} \mathrm{DS}$ to AQDS (Figure 2). In the absence of either perchlorate or cells, no $\mathrm{AH}_{2} \mathrm{DS}$ oxidation was apparent, and in the absence of $\mathrm{AH}_{2} \mathrm{DS}$, no perchlorate reduction was observed data not shown). Analysis of the concentration of $\mathrm{AQDS}$ and $\mathrm{AH}_{2} \mathrm{DS}$ in the medium during incubation revealed that the total anthraquinone concentration remained constant during incubation and was not being biodegraded as a carbon source by the organisms (data not shown). Furthermore, the oxidation of $1.54 \mathrm{~g} \mathrm{~L}^{-1}(4.2 \mathrm{mM}) \mathrm{AH}_{2} \mathrm{DS}$ resulted in the reduction of $98 \mathrm{mg} \mathrm{L}^{-1}(0.99 \mathrm{mM})$ of

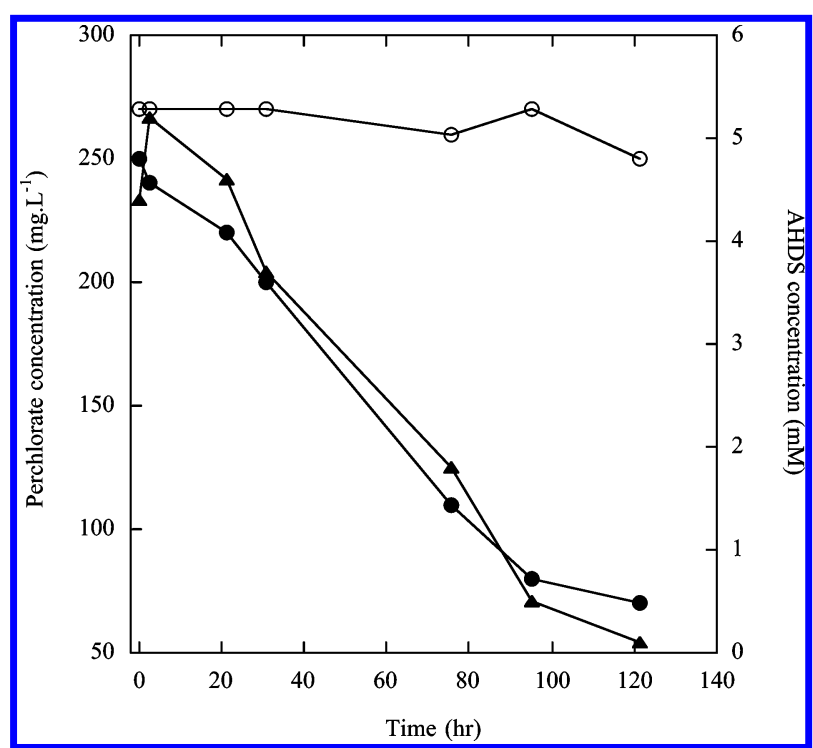

FIGURE 2. Perchlorate reduction coupled to oxidation of the reduced hydroquinone form of the quinone electron shuttle $\mathrm{AH}_{2} \mathrm{DS}$ in anaerobic batch culture by Dechloromonas agitata strain CKB. Closed circles depict perchlorate reduction in the presence of 5 $\mathrm{mM} \mathrm{AH} \mathrm{H}_{2} \mathrm{DS}$, closed triangles depict $\mathrm{AH}_{2} \mathrm{DS}$ oxidation in the presence of $2.5 \mathrm{mM}$ perchlorate, and open circles depict perchlorate reduction in the presence of $5 \mathrm{mM}$ AODS.

perchlorate giving a stoichiometry of 4.24 , which is $106 \%$ of the theoretical value according to

$$
\begin{aligned}
4 \mathrm{C}_{14} \mathrm{H}_{8} \mathrm{O}_{8} \mathrm{~S}_{2}{ }^{2-}\left(\mathrm{AH}_{2} \mathrm{DS}\right)+\mathrm{ClO}_{4}{ }^{-} \rightarrow & 4 \mathrm{C}_{14} \mathrm{H}_{6} \mathrm{O}_{8} \mathrm{~S}_{2}{ }^{2-} \\
& (\mathrm{AQDS})+\mathrm{Cl}^{-}+4 \mathrm{H}_{2} \mathrm{O}
\end{aligned}
$$

These results indicate that perchlorate reduction in the BER was microbially mediated by electrons being shuttled from the cathode surface to the bacterial cells by the AQDS.

Bioelectrical Reduction of Perchlorate by Natural DPRB Populations. Significant perchlorate removal was observed under growth conditions when the cathodic chamber of the BER was filled with sterile anoxic basal media amended with perchlorate, $183 \mathrm{mg} \mathrm{L}^{-1}(500 \mu \mathrm{M})$ AQDS, poised at $-500 \mathrm{mV}$ (vs $\mathrm{Ag} / \mathrm{AgCl}$ ), and inoculated with $10 \% \mathrm{v} / \mathrm{v}$ water from Strawberry Creek on the UC Berkeley campus that had been filtered with $11 \mu \mathrm{m}$ filter paper. Over the first three weeks, almost $200 \mathrm{mg} \mathrm{L}^{-1}$ perchlorate was removed in the enrichment compared to an open-circuit control (Figure 3). At this time, the medium in both the open- and closed-circuit BERs was amended with $0.1 \mathrm{mg} \mathrm{L}^{-1}$ yeast extract for continued cell maintenance. As expected, this resulted in a sharp increase in the amount of perchlorate consumed in both systems, but thereafter perchlorate levels stabilized in the open-circuit control while the closed-circuit BER continued to remove perchlorate. An amendment of perchlorate and an additional $0.1 \mathrm{mg} \mathrm{L}^{-1}$ yeast extract at day 30 showed similar results, and after 70 days of operation, the closed-circuit enrichment had removed $1000 \mathrm{mg} \mathrm{L}^{-1}$ more perchlorate than the open-circuit control.

Isolation and Characterization of Strain VDY. To identify some of the DPRB present in the BER inoculated with Strawberry Creek groundwater, samples $(1 \mathrm{~g})$ were scraped from the surface of the cathode after the 70-day incubation and transferred into fresh basal medium with acetate as the electron donor and perchlorate as the sole electron acceptor. After two weeks incubation, growth was visually apparent in the primary enrichments of these samples. These enrichments were transferred into fresh basal medium $(10 \%$ inoculum) where good growth was again observed after 24 $\mathrm{h}$ as determined by increase in optical density and micro- 


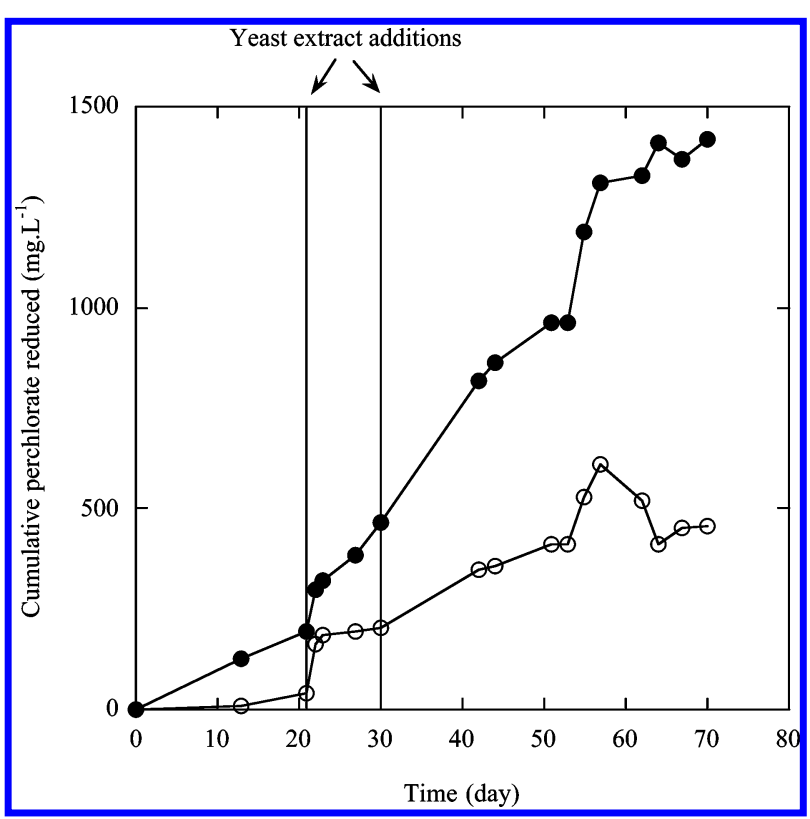

FIGURE 3. Cumulative perchlorate reduction in the bioelectrical reactor and open-circuit control by the indigenous dissimilatory perchlorate-reducing population in Strawberry Creek waters collected from UC Berkeley campus. Closed circles depict cumulative perchlorate removal in the BER, and open circles depict cumulative perchlorate removal in the open-circuit control.

scopic examination. Highly enriched, perchlorate-reducing cultures were obtained by sequential transfer over the following week prior to serial dilution into agar tubes. Small (1-2 mm diameter) pink colonies of consistent morphology were apparent after two weeks of incubation, and a dissimilatory perchlorate-reducing isolate, strain VDY, was selected for further characterization.

Strain VDY was a gram-negative, facultative anaerobe. Cells, $0.2 \mu \mathrm{m}$ diameter by $7 \mu \mathrm{m}$ length, showed a consistent spirillum morphology. Strain VDY completely oxidized organic electron donors to $\mathrm{CO}_{2}$ in the presence of a suitable electron acceptor. Alternatively, strain VDY grew fermentatively in anoxic basal medium amended with glucose $(1.80$ $\left.\mathrm{g} \mathrm{L}^{-1}\right)$, yeast extract $\left(0.1 \mathrm{~g} \mathrm{~L}^{-1}\right)$, and casamino acids $(0.1 \mathrm{~g}$ $\left.\mathrm{L}^{-1}\right)$. Spores were not visible in wet-mounts by phase contrast microscopy, and no growth was observed in fresh acetateperchlorate medium after pasteurization at $80^{\circ} \mathrm{C}$ for $3 \mathrm{~min}$. In addition to acetate, strain VDY used lactate, $\mathrm{AH}_{2} \mathrm{DS}$, ethanol, and $\mathrm{H}_{2}$ as electron donors and perchlorate, chlorate, nitrate, or $\mathrm{O}_{2}$ as electron acceptors. Analyses of the partial $16 \mathrm{~S}$ rDNA sequence (636 bp) indicated that strain VDY was closely related ( $>99 \% 16 \mathrm{~S}$ rDNA sequence identity) to the known DPRB Dechlorospirillum anomalous strain WD in the alpha subclass of the proteobacteria (Figure 4).

Pure Culture BER Studies with Strain VDY. As with the other DPRB tested (D. agitata, D. aromatica, and A. suillum), perchlorate was rapidly removed in the cathodic chamber of a BER poised at $-500 \mathrm{mV}$ when inoculated with strain VDY (Figure 5). Although no significant growth was observed, the cell density in the BER remained constant throughout the incubation, while that of the open-circuit control rapidly declined (data not shown). No perchlorate removal was observed in the open-circuit control, however, in contrast to the results obtained with the other DPRB, strain VDY was capable of reducing perchlorate in the BER in the absence of the mediator AQDS (Figure 5), although this removal was significantly slower than that in the BER amended with AQDS. Analysis of $\mathrm{H}_{2}$ production in the BER indicated that under operational conditions $0.78 \mu \mathrm{g} \mathrm{min}^{-1}$ was produced through electrolysis of water at the surface of the cathode which is

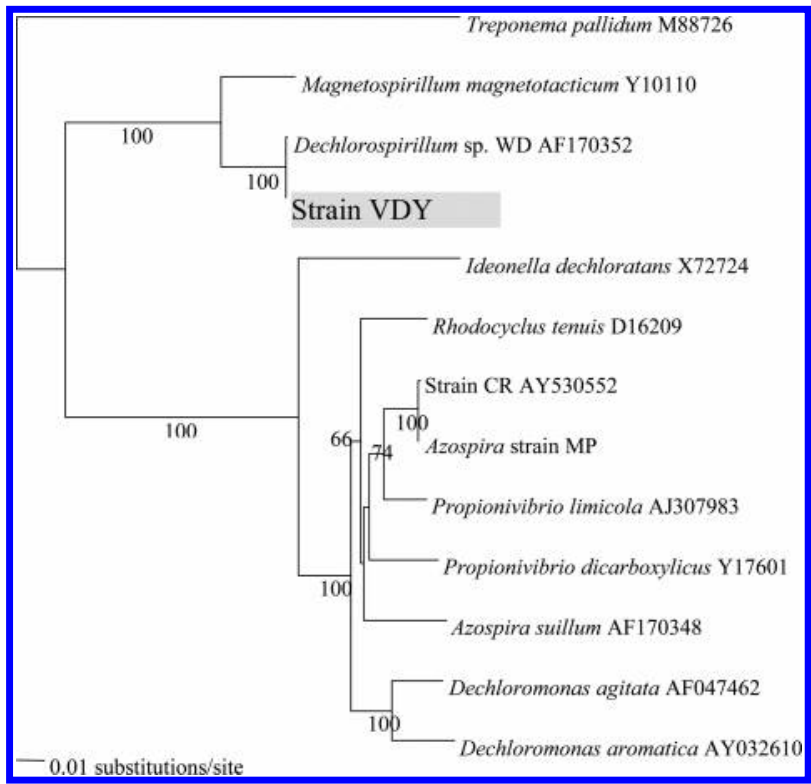

FIGURE 4. Phylogenetic tree resulting from heuristic analysis of a 16S rRNA dataset consisting of 1411 characters using the Kimura 2-parameter distance setting. Bootstrap values of $>\mathbf{5 0} \%$ from $\mathbf{5 0 0}$ replicates are indicated near the relevant nodes.

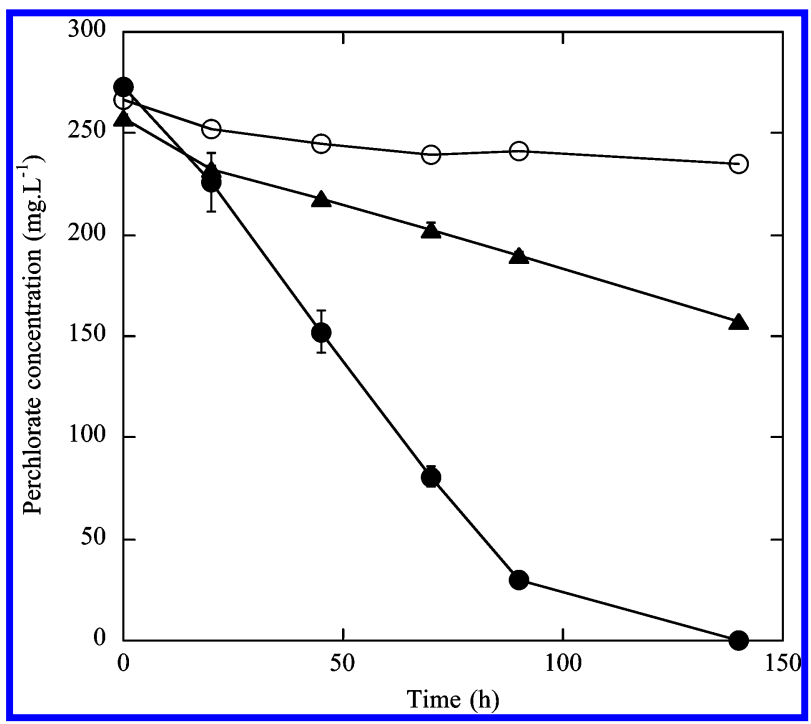

FIGURE 5. Perchlorate removal by strain VDY in a batch culture in the bioelectrical reactor at $-500 \mathrm{mV}$ with and without the electron shuttle AODS. Closed circles depict perchlorate reduction in the $B E R$ in the presence of AODS, closed triangles depict perchlorate reduction in the BER in the absence of AODS, and open circles depict perchlorate reduction in the open-circuit control.

more than enough reducing equivalents to account for the observed reduction of the perchlorate $(2 \mu \mathrm{g} \mathrm{min}-1)$ in the mediator-less BER throughout the incubation assuming a theoretical stoichiometry of

$$
4 \mathrm{H}_{2}+\mathrm{ClO}_{4}^{-} \rightarrow \mathrm{Cl}^{-}+4 \mathrm{H}_{2} \mathrm{O}
$$

Continuous Treatment of Perchlorate in an UFBER. In order to determine the applicability of the BER system combined with strain VDY to the continuous treatment of perchlorate, bench-scale up-flow bioelectrical reactors were constructed in triplicate in the same BER architecture used for the batch experiments. The active chamber contained a packed bed of graphite powder charged by a graphite electrode inserted into the bed to maximize the surface area available for electron donation by the electrode. The reactors 


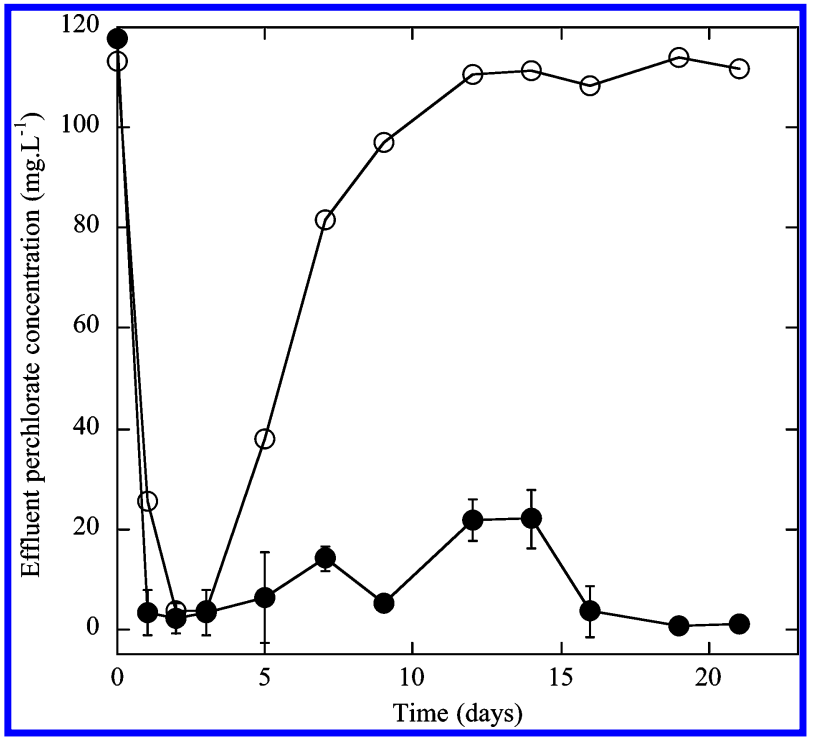

FIGURE 6. Continuous treatment of a perchlorate-containing simulated wastestream amended with $500 \mu \mathrm{M}$ AODS as an electron shuttle in the upflow bioelectrical reactor inoculated with strain VDY. The results depicted are the mean of triplicate determinations. Closed circles depict effluent perchlorate concentrations in the UFBER, and open circles depict effluent perchlorate concentrations in the open-circuit control.

were inoculated with anaerobic active washed cells of strain VDY previously grown on acetate and perchlorate. To promote establishment of the DPRB culture in the bed and to provide a starting baseline for the closed- and open-circuit reactors, acetate $\left(82 \mathrm{mg} \mathrm{L}^{-1}\right)$ was added with strain VDY. AQDS was added at $183 \mathrm{mg} \mathrm{L}^{-1}(500 \mu \mathrm{M})$ to these initial experiments, and the hydraulic loading rate of perchlorate in the influent was initially set at $60 \mathrm{mg} \mathrm{L}^{-1}$ day $^{-1}$ for the first 12 days. As expected in response to the acetate injections, perchlorate levels in the effluent of all reactors were negligible for the first 3 days of operation (Figure 6). However, the perchlorate levels in the open-circuit control soon began to rebound to the influent concentration and stabilized at that level for the remainder of the incubation (Figure 6). In contrast, perchlorate was consistently removed throughout the incubation in the closed-circuit reactors, and at least $80 \%$ removal efficiency was continuously achieved in each of the reactors for the three weeks of operation (Figure 6). Variations in effluent perchlorate concentration throughout the incubation were due to adjustments of the reactor residence time, which was optimized to 3 days at day 16, corresponding to a volumetric loading rate of $40 \mathrm{mg} \mathrm{L}^{-1} \mathrm{day}^{-1}$. After residence time optimization, effluent perchlorate concentrations were consistently below detection for the remainder of the incubation (Figure 6). Furthermore, one of the UFBER replicates was kept operational after the experiment was concluded at day 21 , and while there was no concurrent negative control, this reactor successfully maintained nondetectable perchlorate concentrations in the effluent for a further 40 days without any fluctuations in efficiency (data not shown).

While successful for treating perchlorate, the presence of AQDS was not optimal for water treatment as it adds cost to the treatment and would require an additional step to remove it from the treated effluent. Furthermore, headspace gas analysis indicated that significantly more $\mathrm{H}_{2}$ was produced $\left(3.72 \mu \mathrm{g} \mathrm{min}^{-1}\right)$ in the UFBER configuration than in the batch BERs, probably because of the much larger cathodic surface area, which would theoretically provide enough reducing equivalents to reduce all of the perchlorate at a volumetric loading rate of $66 \mathrm{mg} \mathrm{L}^{-1} \mathrm{day}^{-1}$. In order to determine the

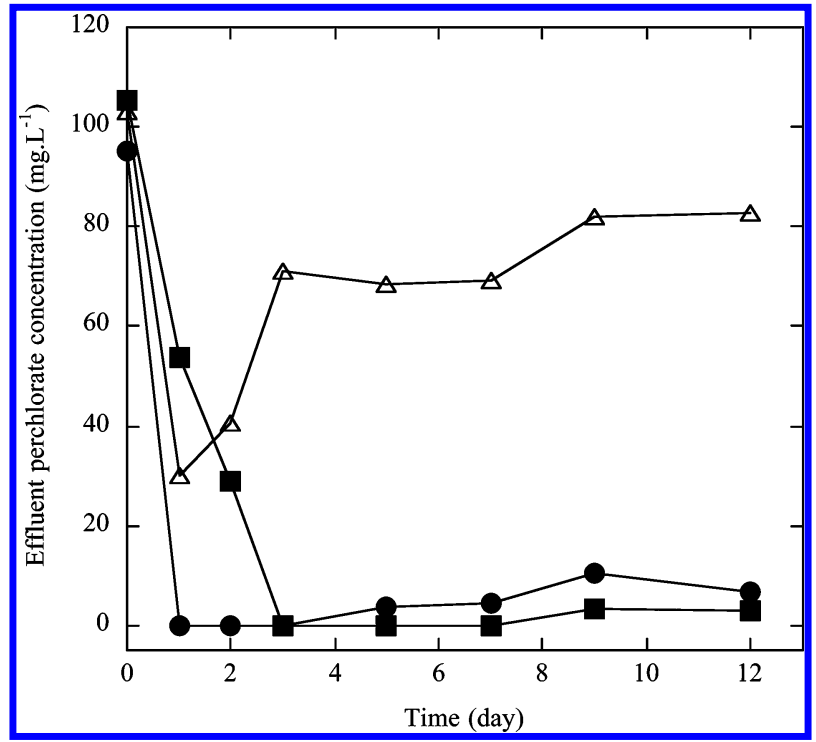

FIGURE 7. Comparison of the continuous-flow treatment of perchlorate in the upflow bioelectrical reactor inoculated with strain VDY in the presence and absence of the electron shuttle AODS. Closed circles depict effluent perchlorate concentrations in the absence of AODS, closed squares depict effluent perchlorate concentrations in the presence of $1 \mu \mathrm{M}$ AODS, and open triangles depict effluent perchlorate concentrations in the open-circuit control.

necessity of the mediator, several UFBERs were constructed, inoculated with an active perchlorate reducing culture of strain VDY, and amended with $59 \mathrm{mg} \mathrm{L}^{-1}$ acetate as before. An initial perchlorate volumetric loading rate of approximately $60 \mathrm{mg} \mathrm{L}^{-1}$ day $^{-1}$ was set. Where necessary, AQDS was added to the influent to give a final concentration of $0.4 \mathrm{mg}$ $\mathrm{L}^{-1}(1 \mu \mathrm{M})$. As predicted, immediate perchlorate removal was apparent in the presence and absence of the AQDS as well as in the open-circuit control because of the initial amendment with acetate. However, the effluent perchlorate content of the open-circuit control rapidly rebounded to levels approaching the influent concentration within $48 \mathrm{~h}$ (Figure 7). In contrast, perchlorate removal was consistent both in the presence and absence of AQDS in the closedcircuit UFBERs for the remainder of the operation. Removal efficiencies were essentially identical regardless of the presence or absence of AQDS, and both UFBERs continuously achieved removal efficiencies of greater than 95\% (Figure 7), indicating that AQDS was not necessary to achieve effective treatment efficiencies at high loading rates in these reactors.

\section{Discussion}

Electrodes as Electron Donors for Microbial Metabolism. These studies represent the first demonstration that electrodes can serve as a primary electron donor for microbial perchlorate reduction and have resulted in the isolation and characterization of a novel isolate, Dechlorospirillum strain VDY, that can exist stably in the BER for extended treatment periods. Previous studies have similarly demonstrated the use of an electrode as the primary electron donor for the dissimilatory reduction of nitrate by Geobacter species (30, 31), fumarate by both Geobacter and Actinobacillus species $(30,32)$, hexavalent uranium by Geobacter species (33), and $\mathrm{CO}_{2}$ by an undefined enrichment (31). Furthermore, electrochemical reduction of soluble iron by a cathode has also been shown to support growth and $\mathrm{CO}_{2}$ fixation by the ironoxidizing Acidithiobacillus species $(34,35)$. In contrast to those studies, however, electrochemically generated $\mathrm{H}_{2}$ through the electrolysis of water at the cathode surface is likely to play a role in the microbial reduction of perchlorate observed in our BER's amended with strain VDY in the 
absence of AQDS. This may also explain the conflicting results obtained with strain VDY and the other DPRB tested in this study, none of which could reduce perchlorate in the BER in the absence of AQDS. This is because $\mathrm{H}_{2}$ is not utilized as an electron donor by the Dechloromonas or Azospira species tested in this study $(24,36-38)$ while, in contrast, physiological characterization revealed that strain VDY could readily use $\mathrm{H}_{2}$ as an electron donor for respiration.

However, other alternatives to $\mathrm{H}_{2}$ mediation may also exist. The previous Geobacter-based studies showed members of this genus were able to directly access electrons off the electrode surface (30) without the need for electrolytically produced $\mathrm{H}_{2}$. Geobacter species are similarly known to pass electrons directly onto an anodic surface in the absence of electron shuttling compounds when oxidizing organic electron donors (39). Whether or not these organisms use a reversal of a single pathway to mediate these contrasting electron transfers is unknown. Additionally, microbially produced electron shuttles have also been shown to play an important role in electron transfer in the anodic chamber of microbial fuel cells (40). While strain VDY has been shown to utilize hydrogen for the reduction of perchlorate, the possibility still exists that it may also utilize electrons directly from the electrode surface or produce an electron shuttling compound to further supplement its metabolism of perchlorate in the cathodic chamber, and this represents an important future direction for this research. Regardless of the mechanism of electron transfer off the electrode surface, the removal of AQDS or any other additional organic carbon source from the BER system is advantageous for treatment cost-effectiveness as well as effluent water quality.

Reactor Effectiveness. The results obtained in this study indicate that the stimulation of microbial perchlorate reduction in the UFBER is already competitive with existing state of the art bioreactors without any electrochemical optimization. Current high-throughput treatment of concentrated perchlorate wastestreams is over $400 \mathrm{mg} \mathrm{L}^{-1}$ day $^{-1}$ (41); however, average volumetric loads are one tenth of that. The UFBER in this study showed consistent removal of $60 \mathrm{mg} \mathrm{L}^{-1}$ reactor volume day $^{-1}$, without addition of a chemical electron donor. This is significant given the inherent inefficiencies of the H-style electrochemical cell employed for these studies. The limitations to microbial stimulation stem from high internal resistance that can be overcome easily with design modifications already in use for a variety of microbial fuel cell (MFC) technologies. These modifications included increased cation-specific membrane surface area or removal of the cation-specific membrane altogether, as well as decreased distances between the anode and cathode. Given the order of magnitude improvements in power production from these types of modifications in MFCs (42), it would be expected that similar modifications would improve UFBER performance for perchlorate treatment.

Significance. The results presented here indicate that microbial perchlorate reduction can be coupled to the removal of electrons off the surface of an electrode. This has important implications with regard to the continuous longterm treatment of perchlorate-contaminated waters and wastestreams. Although previous studies have resulted in the development of various alternative bioreactor designs (13), all of these are limited by the requirement for a continuous addition of a suitable chemical electron donor. Because microbial perchlorate reduction is generally inhibited by the presence of $\mathrm{O}_{2}$ and to some extent nitrate $(29,43)$, excess electron donor must be added to biologically remove these components from reactor influents prior to the stimulation of perchlorate reduction. Such additions must be carefully monitored to prevent the presence of residual labile electron donor in the reactor effluent which may result in biofouling of distribution systems and the formation of trihalomethanes $(14,15)$. This is especially true if the total electron accepting capacity of the perchlorate present in the contaminated stream is small relative to that of the nitrate and dissolved $\mathrm{O}_{2}$ content which is the case for most contaminated waters (9). Bioelectrical reduction at the cathode surface overcomes many of these issues because no chemical electron donor is added to the bioreactor.

In conclusion, the results presented here demonstrate the exciting potential for the application of bioelectrical reduction for the treatment of perchlorate contamination without many of the limitations normally associated with bioreactor-based processes.

\section{Acknowledgments}

The authors wish to acknowledge Ms. Susan M. O'Connor and Mr. David C. Coates for advice in the design and operation of the BER. Funding for this work was provided to JDC through the DOE Laboratory Directed Research and Development (LDRD) program.

\section{Literature Cited}

(1) Stanbury, J. B.; Wyngaarden, J. B. Effect of perchlorate on the human thyroid gland. Metabolism 1952, 1, 533-539.

(2) Wolff, J. Perchlorate and the thyroid gland. Pharmacol. Rev. 1998, 50, 89-105.

(3) Clark, J. J. J. Toxicology of perchlorate. In Perchlorate in the Environment; Urbansky, E. T., Ed.; Kluwer Academic/Plenum: New York, 2000.

(4) Motzer, W. E. Perchlorate: problems, detection, and solutions. Environ. For. 2001, 2, 301-311.

(5) Urbansky, E. T. Perchlorate chemistry: implications for analysis and remediation. Biorem. J. 1998, 2, 81-95.

(6) Urbansky, E. T. Perchlorate as an environmental contaminant. Environ. Sci. Pollut. Res. 2002, 9, 187-192.

(7) Wallace, W.; Ward, T.; Breen, A.; Attaway, H. Identification of an anaerobic bacterium which reduces perchlorate and chlorate as Wolinella succinogenes. J. Ind. Microbiol. 1996, 16, 68-72.

(8) Urbansky, E. T.; Brown, S. K. Perchlorate retention and mobility in soils. L. Environ. Monit. 2003, 5, 455-462.

(9) Coates, J. D.; Achenbach, L. A. Microbial perchlorate reduction: rocket fuelled metabolism. Nat. Rev. Microbiol. 2004, 2, 569580.

(10) Coates, J. D.; Achenbach, L. A. The microbiology of perchlorate reduction and its bioremediative application. In Perchlorate, Environmental Occurrence, Interactions, and Treatment; Gu, B., Coates, J. D., Eds.; Springer Publishers: New York, 2006.

(11) Coates, J. D.; Michaelidou, U.; Bruce, R. A.; O'Connor, S. M.; Crespi, J. N.; Achenbach, L. A. The ubiquity and diversity of dissimilatory (per)chlorate-reducing bacteria. Appl. Environ. Microbiol. 1999, 65, 5234-5241.

(12) Brown, J. C.; Anderson, R. D.; Min, J. H.; Boulos, L.; Prasifka, D.; Juby, G. J. G. Fixed bed biological treatment of perchloratecontaminated drinking water. J. Am. Water Works Assoc. 2005, $97,70-81$.

(13) Xu, J.; Song, Y.; Min, B.; Steinberg, L.; Logan, B. E. Microbial degradation of perchlorate: principles and applications. Environ. Eng. Sci. 2003, 20, 405-422.

(14) Rook, J. J. Haloforms in drinking water. J. Am. Water Works Assoc. 1976, 68, 168-172.

(15) Bellar, T. A.; Lichtenberg, J. J.; Kroner, R. C. Occurrence of organohalides in chlorinated drinking waters. J.Am. Water Works Assoc. 1974, 66, 703-706.

(16) Nerenberg, R.; Rittmann, B. E. Hydrogen-based, hollow-fiber membrane biofilm reactor for reduction of perchlorate and other oxidized contaminants. Water Sci. Technol. 2004, 49, 223-230.

(17) Logan, B. E.; LaPoint, D. Treatment of perchlorate- and nitratecontaminated groundwater in an autotrophic, gas phase, packed-bed bioreactor. Water Res. 2002, 36, 3647-3653.

(18) Chapelle, F. H. Ground-water microbiology and geochemistry; John Wiley and Sons: New York, 1993.

(19) Brown, C. J.; Coates, J. D.; Schoonen, M. A. Localized sulfatereducing zones in a coastal plain aquifer. Ground Water 1999, $37,505-516$

(20) Siegal, D. I.; McFarland, W. E.; Byrnes, T. R. Geochemical implications of mineral scaling in remediation equipment; 
Stearns and Wheler Environmental Engineers and Scientists: Cazenovla, NY, 1992.

(21) Balch, W. E.; Fox, G. E.; Magrum, L. J.; Woese, C. R.; Wolfe, R. S. Methanogens: reevaluation of a unique biological group. Microbiol. Rev. 1979, 43, 260-296.

(22) Hungate, R. E. A roll tube method for cultivation of strict anaerobes. Methods Microbiol. 1969, 3B, 117-132.

(23) Miller, T. L.; Wolin, M. J. A serum bottle modification of the Hungate technique for cultivating obligate anaerobes. Appl. Microbiol. 1974, 27, 985-987.

(24) Bruce, R. A.; Achenbach, L. A.; Coates, J. D. Reduction of (per)chlorate by a novel organism isolated from a paper mill waste. Environ. Microbiol. 1999, 1, 319-331.

(25) Maidak, B. L.; Olsen, G. J.; Larsen, N.; Overbeek, R.; McCaughey, M. J.; Woese, C. R. The RDP (Ribosomal Database Project). Nucleic Acids Res. 1997, 25, 109-111.

(26) Benson, D. A.; Boguski, M. S.; Lipman, D. J.; Ostell, J.; Ouellette, B. F. GenBank. Nucleic Acids Res. 1998, 26, 1-7.

(27) Gilbert, D. G. 1.9a157 ed.; Biocomputing Office, Biology Dept., Indiana University: Bloomington, IN, 1993.

(28) Swofford, D. L. 4.0. Sinauer Associates, Sunderland, MA. ed.; Smithsonian Institution: Washington, DC, 1999.

(29) Chaudhuri, S. K.; O'Connor, S. M.; Gustavson, R. L.; Achenbach, L. A.; Coates, J. D. Environmental factors that control microbial perchlorate reduction. Appl. Environ. Microbiol. 2002, 68, 44254430.

(30) Gregory, K. B.; Bond, D. R.; Lovley, D. R. Graphite electrodes as electron donors for anaerobic respiration. Environ. Microbiol. 2004, 6, 596-604.

(31) Park, H. I.; Kim, D. K.; Choi, Y. J.; Pak, D. Nitrate reduction using an electrode as direct electron donor in a biofilm-electrode reactor. Process Biochem. 2005, 40, 3383-3388.

(32) Park, D. H.; Laivenieks, M.; Guettler, M. V.; Jain, M. K.; Zeikus, J. G. Microbial utilization of electrically reduced neutral red as the sole electron donor for growth and metabolite production. Appl. Environ. Microbiol. 1999, 65, 29122917.

(33) Gregory, K. B.; Lovley, D. R. Remediation and recovery of uranium from contaminated subsurface environments with electrodes. Environ. Sci. Technol. 2005, 39, 89438947.
(34) Nakasano, S.; Matsumoto, N.; Saiki, H. Electrochemical cultivation of Thiobacillus ferrooxidans by potential control. Bioelectrochem. Bioenerg. 1997, 43, 61-66.

(35) Blake, R. C.; Howard, G. T.; McGinness, S. Enhanced yields of iron-oxidizing bacteria by in situ electrochemical reduction of soluble iron in the growth medium. Appl. Environ. Microbiol. 1994, 60, 2704-2710.

(36) Coates, J. D.; Chakraborty, R.; Lack, J. G.; O'Connor, S. M.; Cole, K. A.; Bender, K. S.; Achenbach, L. A. Anaerobic benzene oxidation coupled to nitrate reduction in pure culture by two strains of Dechloromonas. Nature 2001, 411, 1039-1043.

(37) Achenbach, L. A.; Bruce, R. A.; Michaelidou, U.; Coates, J. D. Dechloromonas agitata gen. nov, sp. nov. and Dechlorosoma suillum gen. nov., sp. nov., two novel environmentally dominant (per)chlorate-reducing bacteria and their phylogenetic position. Int. J. Syst. Evol. Microbiol. 2001, 51, 527-533.

(38) Coates, J. D.; Michaelidou, U.; O'Connor, S. M.; Bruce, R. A.; Achenbach, L. A. The diverse microbiology of (per)chlorate reduction. In Perchlorate in the Environment; Urbansky, E. D. Ed.; Kluwer Academic/Plenum: New York, 2000; pp 257270.

(39) Bond, D. R.; Lovley, D. R. Electricity production by Geobacter sulfurreducens attached to electrodes. Appl. Environ. Microbiol. 2003, 69, 1548-1555.

(40) Rabaey, K.; Boon, N.; Siciliano, S. D.; Verhaege, M.; Verstraete, W. Biofuel cells select for microbial consortia that self-mediate electron transfer. Appl. Environ. Microbiol. 2004, 70, 53735382 .

(41) Hatzinger, P. B. Perchlorate biodegradation for water treatment. Environ. Sci. Technol. 2005, 39, 239A-247A.

(42) Lovley, D. R. Bug juice: harvesting electricity with microorganisms. Nat. Rev. Microbiol. 2006, 4, 497-508.

(43) O'Connor, S. M.; Coates, J. D. A universal immuno-probe for (per)chlorate-reducing bacteria. Appl. Environ. Microbiol. 2002, $68,3108-3113$.

Received for review November 21, 2006. Revised manuscript received January 3, 2007. Accepted January 3, 2007.

ES062772M 